\title{
Perancangan Program Pengajuan Pemasangan Wifi Publik Kota Depok Berbasis Web
}

\author{
Apriyanto $^{1}$, Enok Tuti Alawiah ${ }^{2}$, Mochamad Bayu Ramadhan Mubaraq ${ }^{3}$ \\ 1,2,3Universitas Bina Sarana Informatika \\ 1apriyanto.apo@bsi.ac.id, ${ }^{2} e n o k . e t w @ b s i . a c . i d,{ }^{3}$ mbayurm@gmail.com
}

\begin{abstract}
Wireless Fidelity (Wifi) is a form of development of wireless connection technology using radio waves. The use of Wifi is now very common, we can find everywhere, be it publik spaces such as parks to private spaces such as homes and offices. One of the advantages of using a Wifi network is that a single Hotspot (Wifi) point can be used by several different devices. Because of this practicality, many people now use Wifi for their daily activities such as reading news, opening social media, to work and education needs. However, it was found that there are still many people who have not been able to enjoy this Wifi facility because every installation of a Hotspot (Wifi) point requires a cost that is not cheap and every month requires a subscription fee. For this, the design of the Depok city publik Wifi application program was made with the aim of making it easier for the publik to apply for Wifi installation because it can be done online as well as with other purposes, namely so that the community, especially the city of Depok, can find out about information related to locations where Wifi is already available. The research method used is the waterfall method with the SDLC development model. Data collection was carried out by interview, survey and observation. Analysis tools use Entity Relationship Diagram and Logical Record Structure (LRS). It is hoped that with this application, the community, especially Depok residents, can easily get free Wifi services, including for places such as parks, community halls, posyandu, places of worship, Rukun Warga offices, and others by installing free Wifi in areas.
\end{abstract}

Keywords: Wifi; Design; Waterfall, ERD; LRS

\begin{abstract}
Abstrak
Wireless Fidelity (Wifi) merupakan salah satu bentuk perkembangan dari teknologi koneksi tanpa kabel dengan menggunakan gelombang radio. Penggunaan Wifi sekarang ini sudah sangat lazim kita jumpai dimana-mana baik itu ruang publik seperti taman sampai ruang privat seperti rumah dan kantor. Salah satu keunggulan menggunakan jaringan Wifi adalah satu titik Hotspot (Wifi) bisa digunakan oleh beberapa perangkat device berbeda. Karena kepraktisan inilah banyak dari masyarakat sekarang yang menggunakan Wifi untuk berkegiatan sehari-hari seperti membaca berita, membuka social media, sampai keperluan pekerjaan dan pendidikan. Namun didapati bahwa masih banyak masyarakat yang belum bisa menikmati fasilitas Wifi ini dikarenakan setiap pemasangan titik Hotspot (Wifi) diperlukan biaya yang tidak murah dan setiap bulannya memerlukan biaya berlangganan. Untuk hal tersebut, perancangan program pengajuan Wifi publik Kota Depok dibuat dengan tujuan agar mempermudah masyarakat dalam mengajukan pemasangan Wifi karena bisa dilakukan secara online serta dengan tujuan lainnya yaitu agar masyarakat khususnya kota Depok dapat mengetahui mengenai informasi terkait lokasi yang sudah tersedia Wifi. Metode penelitian yang digunakan dengan metode waterfall dengan model pengembangan SDLC. Pengumpulan data dilakukan dengan wawancara, survey dan observasi. Alat Bantu analisis menggunakan Entity Relationship Diagram dan Logical Record Structure (LRS). Diharapkan dengan adanya aplikasi ini masyarakat khususnya warga Depok dapat dengan mudah mendapatkan pelayanan Wifi gratis antara lain untuk tempat-tempat seperti taman, balai warga, posyandu, tempat ibadah, kantor Rukun Warga, dan lain-lainnya dengan cara pemasangan Wifi gratis pada area-area tersebut.
\end{abstract}

Kata Kunci: Wifi; Perancangan; Waterfall; ERD; LRS 


\section{PENDAHULUAN}

Dewasa ini Teknologi informasi dan komunikasi berkembang dengan sangat pesat hal ini tentu saja sejalan dengan kebutuhan akses internet yang tinggi di kalangan masyarakat, baik untuk bertukar informasi, membuka sosial media, mencari artikel, mengirim tugas bahkan untuk keperluan pekerjaan dan bisnis. Keadaan ini membuat pihak pemerintahan maupun swasta berlomba-lomba untuk memberikan pelayanan yang terbaik kepada masyarakat baik yang sifatnya berorientasi profit maupun non-profit. Untuk memberikan kemudahan dalam mengakses informasi bagi warganya, Pemerintah Kota Depok melalui Dinas Komunikasi dan Informatika (DISKOMINFO) berupaya untuk mengoptimalkan pemanfaatan Teknologi Informasi dan Komunikasi (TIK) secara optimal dengan mengimplementasikan e-Government salah satunya dengan cara pemasangan titik Hotspot (Wifi) gratis di beberapa wilayah yang ada di Kota Depok. Dampak positif dari e-Government adalah memperluas partisipasi publik dimana masyarakat dimungkinkan untuk terlibat aktif dalam pengambilan keputusan/kebijakan oleh pemerintah. (Dewi et al., 2020). Hal ini bertujuan untuk meningkatkan kualitas pelayanan publik sehingga dapat dipastikan bahwa program tersebut selaras dengan tujuan Pemerintahan yang baik (good governance) dengan terselenggaranya pelayanan publik yang baik melalui implementasi e-Government, serta mengoptimalkan peran masyarakat dalam implementasi e-Government dalam upaya peningkatan pelayanan publik. Pemasangan Wifi publik gratis ini akan terfokus pada lokasi-lokasi publik seperti taman, balai warga, posyandu, komunitas, tempat ibadah, gedung serbaguna dan sebagainya. Dengan pemanfaatan teknologi ini individu dapat mengakses jaringan internet melalui gadget yang mereka miliki di lokasi-lokasi dimana hotspot disediakan. Sebagai salah satu Kota penyangga Ibu Kota Jakarta, Kota Depok merupakan wilayah yang sangat strategis dalam pengembangan jaringan Teknologi Informasi dan Komunikasi (TIK). Selain itu, banyaknya perguruan tinggi serta berbagai komunitas yang bergerak di bidang IT, telah membuat Kota Depok menjadi kota yang memiliki jumlah penduduk dengan tingkat penggunaan internet tertinggi se-Jabodetabek. Namun dengan meningkatnya penggunaan Wifi publik di Kota Depok, masih terdapat beberapa kendala dimana masyarakat kesulitan untuk mengajukan pemasangan layanan Wifi publik serta informasi untuk mengetahui lokasi mana saja yang sudah tersedia Wifi publik, hal ini tentu saja dikarenakan kurangnya informasi yang didapat oleh masyarakat. Oleh karena itu berdasarkan permasalahan yang sudah dijelaskan sebelumnya maka tujuan penulisan ini adalah untuk membangun sebuah program website pengajuan pemasangan Wifi publik secara online hal ini bertujuan agar meningkatkan efektivitas dan efisiensi kinerja dari penerapan $e$ Government di Dinas Komunikasi dan Informatika Kota Depok, serta mempermudah masyarakat untuk mengetahui informasi yang berkaitan dengan pengajuan pemasangan layanan Wifi Publik di Kota Depok.

\section{KERANGKA TEORI}

\subsection{Metode Pengembangan Perangkat Lunak}

Metode yang digunakan pada pembuatan perangkat lunak ini menggunakan model waterfall dikutip dari jurnal (Tabrani \& Eni, 2017), menurut Rosa dan Shalahuddin (2013:28) model waterfall terbagi menjadi lima tahapan yaitu:

1. Analisis Kebutuhan Perangkat Lunak

Analisis kebutuhan sistem dan software adalah proses menentukan sistem secara total dan menentukan data yang akan dipakai untuk website berita ini. 


\section{Desain Sistem (System Design)}

Desain perangkat lunak adalah proses multi langkah yang fokus pada desain pembuatan program perangkat lunak termasuk struktur data, arsitektur perangkat lunak, representasi antarmuka, dan prosedur pengkodean. Tahap ini mentranslasi kebutuhan perangkat lunak dari tahap analisis kebutuhan ke representasi desain agar dapat diimplementasikan menjadi program pada tahap selanjutnya. Desain perangkat lunak yang dihasilkan pada tahap ini juga perlu didokumentasikan.

3. Pembuatan Kode Program

Desain harus ditranslasikan kedalam program perangkat lunak. Hasil dari tahap ini adalah program komputer sesuai dengan desain yang telah dibuat pada tahap desain.

4. Pengujian Sistem (System Testing)

Pengujian fokus pada perangkat lunak secara dari segi lojik dan fungsional dan memastikan bahwa semua bagian sudah diuji. Hal ini dilakukan untuk meminimalisir kesalahan (error) dan memastikan keluaran yang dihasilkan sesuai dengan yang diinginkan.

5. Perawatan (Maintance)

Tidak menutup kemungkinan sebuah perangkat lunak mengalami perubahan ketika sudah dikirimkan ke user. Kesalahan terjadi karna adanya kesalahan yang muncul dan tidak tidak terdeteksi saat pengujian atau perangkat lunak harus beradaptasi dengan lingkungan baru. Tahap perawatan/pemeliharaan ini dapat mengulangi proses pengembangan mulai dari analisis spesifikasi untuk perubahan perangkat lunak yang sudah ada, tapi tidak untuk membuat perangkat lunak baru.

\subsection{Pustaka Rujukan}

\subsubsection{Konsep Dasar Web}

Menurut Nurmalasari Anna di jurnal (Nurmalasari et al., 2019) mengatakan bahwa, "Situs website awalnya merupakan suatu layanan sajian informasi yang menggunakan konsep hiperlink yang memudahkan surfer (sebutan bagi pemakai komputer yang melakukan penyelusuran informasi di Internet) untuk mendapatkan informasi dengan cukup mengklik suatu link berupa teks atau gambar maka informasi dari teks atau gambar akan ditampilkan secara lebih terperinci (detail)". Website adalah sumber dari halaman-halaman situs, yang terangkum dalam sebuah domain, yang ada di dalam WWW (World Wide Web) di Internet. Halaman web adalah dokumen yang dituliskan dengan format HTML atau kepanjangan dari (Hyper Text Markup Language), yang bisa diakses kapanpun melalui HTTP. HTTP adalah protokol yang dapat menyampaikan informasi melalui server website untuk ditampilkan kepada pemakai melalui web browser. Website juga dapat dikategorikan menjadi dua yaitu website statis dan website dinamis. (Trimarsiah \& Arafat, 2017).

Menurut Hidayatullah dan Kawistara di jurnal (Ayu \& Permatasari, 2018) Internet atau didefinisi sebagai dua komputer atau mungkin lebih yang memiliki konektivitas yang membentuk jaringan komputer sampai jutaan komputer di seluruh dunia secara global, yang saling berinteraksi dan bertukar informasi. Dengan ilmu pengetahuan internet ialah perpustakaan besar yang mempunyai jutaan hingga miliaran informasi yang dapat berupa grapich, text, audio, dan animasi berbentuk media elektronik. Untuk segi komunikasi, internet merupakan sarana yang efisien untuk melakukan pertukaran informasi jarak jauh. Web Browser adalah software yang digunakan untuk mengambil, menampilkan dan menyebarkan informasi atau data di dalam internet. Menurut Yudhanto dan Helmi di dalam (Web Programing, 2017) Web server merupakan software yang berfungsi untuk menerima permintaan yang dikirimkan melalui browser, kemudian memberikan tanggapan permintaan dengan bentuk halaman situs web atau lebih 
umumnya di dalam dokumen HTML. Pada sisi perangkat lunak atau software, kegunaan web server ialah sebagai pusat untuk memproses permintaan yang diterima dari browser. Word Wide Web (WWW) merupakan kumpulan web server di seluruh dunia yang dapat menyediakan data dan informasi untuk dapat digunakan secara massal (Web Programing, 2017). Sedangkan Menurut Kustiyahningsih dan Devie Rosa Anamisa dalam Fridayanthie \& Mahdiati di jurnal (Anhar, 2017) menyebutkan bahwa informasi WWW ini disimpan pada web server untuk dapat diakses dari jaringan browser terlebih dahulu, seperti Internet Explorer atau Mozilla Firefox".

\subsubsection{Bahasa Pemrograman}

Bahasa pemrogaram adalah instruksi standar untuk memerintah komputer mulai dari aturan sintak dan semantik yang dipakai untuk mendefinisikan program komputer yang digunakan dalam menulis program (Rosidah;., 2018). Untuk rancang bangun yang dibuat ini ada beberapa bahasa pemrograman yang dipakai dan sekaligus framework dan library-nya seperti PHP, dan Javascript. Hypertext Preprocessor atau kepanjangan dari PHP merupakan salah satu bahasa pemrograman open source yang cocok atau dikhususkan untuk pengembangan aplikasi web dan dapat dimasukkan pada sebuah script HTML.PHP merupakan bahasa scripting server - side, dimana memproses datanya dilakukan pada sisi server. Sederhananya, serverlah yang akan menerjemahkan skrip program, baru kemudian hasilnya akan dikirim kepada client yang melakukan permintaan (Firman et al., 2016). Menurut survey yang lakukan oleh Sitepoint.com pada Desember 2013 dalam popularitas framework PHP, Laravel menduduki urutan teratas.(Ruli Erinton, Ridha Muldina Negara, 2017). Menurut Henderson dalam (Pahlevi et al., 2018) CSS kepanjangan dari Cascading Style Sheet adalah bahasa-bahasa yang merepresentasikan halaman web. Seperti warna, layout, dan font. Dengan memakai CSS, seorang programmer dapat membuat halaman web yang beradaptasi dengan berbagai macam ukuran layar. Menurut Henderson (Pahlevi et al., 2018) HTML (Hyper Text Mark Up Language) merupakan bahasa yang digunakan untuk mendeskripsikan struktur sebuah halaman web. HTML berfungsi untuk mempublikasi dokumen online. Statement dasar dari HTML disebut tags. Sebuah tag diterjemahkan di dalam sebuah kurung siku (く>). Tags yang ditunjuk untuk sebuah dokumen atau bagian dari suatu dokumen haruslah dibuat berupa pasangan. Terdiri dari tag pembuka dan tag penutup. Dimana tag penutup menggunakan tambahan tanda garis miring (/) di awal nama tag. Menurut Henderson (Pahlevi et al., 2018) JavaScript pertama kali dikembangkan pada pertengahan dekade 90'an. Meskipun mempunyai nama yang hampir sama, JavaScript berbeda dengan Bahasa Java. Untuk penulisannya, JavaScript dapat dimasukkan ke dalam dokumen HTML ataupun di jadikan dokumen terpisah yang kemudian di import untuk dokumen yang ingin dituju.. Menurut Spurlock dalam (Pahlevi et al., 2018) menyatakan bahwa Bootsrap adalah sebuah framework untuk CSS dan berupa produk open source yang dibuat oleh Mark Otto dan Jacob Thornton. Menurut Beighley dalam (Pahlevi et al., 2018) menjelaskan JQuery adalah open source add-on pustaka JavaScript yang menekankan pada interaksi antara JavaScript dan HTML. JQuery adalah script JavaScript yang ditulis dan tinggal menambahkan satu atau beberapa baris script untuk memanggil JQuery.

\subsubsection{Basis Data}

Menurut (Hariyanto, 2019) Basis data adalah sekumpulan informasi yang diatur dalam cara tertentu hingga sebuah program komputer dapat dengan cepat memilih data yang diinginkan. Basisdata dapat diibaratkan sebagai sistem pengarsipan elektronis. Basis data tradisional terdiri dari field, record, dan file. Field adalah item tertentu dari informasi; record adalah sekumpulan field; dan file adalah kumpulan record. Dalam basis data hypertext, setiap obyek, apakah itu merupakan teks, gambar atau film, dapat dihubungkan dengan obyek lainnya. Untuk mengakses 
informasi dari basisdata, diperlukan data base management system (DBMS). DBMS adalah kumpulan program yang memungkinkan pengguna memasukan, mengatur, atau memilih data dari basis data.

\subsubsection{Model Pengembangan Perangkat Lunak}

Menurut Sukamto dan Shalahuddin dalam (Jurnal Petir, 2018) Model air terjun (waterfall) adalah Model sekuensial linier (sequential Linear) atau alur hidup klasik (classic life cycle). Model waterfall memberikan pendekatan alur hidup perangkat lunak secara tersusun dari analisis, desain, pengkodean, pengujian dan tahap pendukung.

\subsubsection{Struktur Navigasi}

Dalam pembuatan website, bagian yang harus diperhatikan sebelum merancang tampilan halaman web adalah pembuatan struktur navigasi. Ada empat struktur dasar yang digunakan, yaitu linear, hierarkis, nonlinear, dan komposit menurut Binanto (Yuni Eka Achyani, 2018).

\subsubsection{ERD (Entity Relationship Diagram) Dan LRS (Logical Record Structure)}

Menurut Simarmata di dalam (Tias Mahdiati, 2016) Entity RelationShip Diagram (ERD) adalah perangkat pemodelan data utama dan bisa mambantu mengorganisasi data dalam proyek ke dalam entitas dan menentukan hubungan antar entitas. Proses memungkinkan analis menghasilkan struktur basis data dapat disimpan dan diambil dengan mudah. Menurut Simarmata dan paryudi di dalam (Tias Mahdiati, 2016) Logical Record Structured (LRS) adalah gambaran dari susunan record pada tabel-tabel yang tersusun dengan hasil relasi pada himpunan entitas.

\subsubsection{Black Box Testing}

Pengujian perangkat lunak dari segi spesifikasi fungsional tanpa menguji desain dan kode program untuk mengetahui apakah fungsi, masukan dan keluaran dari perangkat lunak sesuai dengan spesifikasi yang dibutuhkan. Dan dengan metode ini dapat diketahui jika fungsionalitas masih dapat menerima masukan data yang tidak diharapkan maka menyebabkan data yang disimpan kurang valid (Cholifah et al., 2018)

\section{METODOLOGI}

Metodologi penelitian yang digunakan dengan menggunakan Metode Pengembangan Perangkat Lunak Dengan menggunakan model waterfall yang terbagi menjadi lima tahapan yang dimulai dari tahapan analisis kebutuhan dan diakhiri dengan tahapan perawatan. Teknik pengumpulan data menggunakan wawancara, observasi dan studi pustaka. Wawancara dilakukan dengan tanya jawab pada pihak-pihak terkait pemasangan Wifi dan tata caranya. Observasi dilakukan dengan terjun langsung ke area penelitian dan melakukan pengamatan secara langsung tentang cara pengajuan pemasangan Wifi publik. Untuk Studi pustaka dilakukan dengan mencari referensi melalui bukubuku atau literatur-literatur yang berhubungan dengan makalah penelitian.

\section{HASIL DAN PEMBAHASAN}

\subsection{Analisis Kebutuhan}

Tahap analisa kebutuhan pada perancangan program pengajuan pemasangan Wifi publik pada Dinas Komunikasi dan Informatika Kota Depok dilakukan dengan mengidentifikasi apa saja yang perlu dilakukan oleh sistem. Dalam tahap ini para pengguna sistem memiliki akses yang berbeda sesuai dengan kebutuhan mereka dan dibagi menjadi: 
1. Admin

Dalam sistem ini admin memiliki beberapa hal yang dapat dilakukan seperti:

a. Mengelola data pengajuan yang didapat dari masyarakat dan diseleksi apakah layak untuk dilakakukan pemasangan atau tidak.

b. Mengelola data lokasi pemasangan untuk di tampilkan pada halaman depan website seperti edit lokasi

c. Mengolah data tempat, dimana admin dapat menambahkan, atau mengedit sesuai dengan kebutuhan sistem.

d. Admin dapat menambahkan data admin baru, dan edit admin.

e. Mengelola data pengguna user, yaitu admin dapat melihat data user.

\section{User dengan login akun}

Dalam sistem ini user dengan login akun memiliki beberapa hal yang dapat dilakukan seperti:

a. Membuat pengajuan pemasangan Wifi publik.

b. Mengelola profil.

c. Lupa password.

d. Bisa melihat lokasi yang sudah terpasang Wifi publik.

e. Melihat status pengajuan diterima, pending ataupun ditolak.

f. Cetak bukti berita di setujui oleh website.

3. User tanpa login akun

Dalam sistem ini user tanpa login akun memiliki beberapa hal yang dapat dilakukan seperti:

a. Dapat melihat lokasi yang sudah terpasang Wifi publik.

b. Bisa membuat akun melalui daftar akun.

c. Melihat profile website berita dan manual book.

\subsection{Rancangan Dokumen}

A. Rancangan Dokumen Masukan (Input)

Rancangan ini bertujuan untuk mengetahui informasi yang akan diolah, sehingga hasil keluarannya (output) yang dihasilkan sesuai dengan kebutuhan, Adapun dokumen sebagai berikut:

1. Nama Dokumen: Data user

Fungsi : Untuk penyimpanan data user pengajuan yang sudah mendaftar

Sumber : User

Tujuan : Admin

Media : Komputer

Frekuensi : Saat user sudah daftar akun

Bentuk : web page

2. Nama Dokumen: Data pengajuan pemasangan Wifi

Fungsi : Sebagai Data pengajuan dari masyarakat

Sumber : User

Tujuan : Admin

Media : Komputer

Frekuensi $\quad$ Ketika user mengajukan pemasangan Wifi 
Bentuk : Web page

3. Nama Dokumen: Data lokasi pemasangan

Fungsi : Informasi lokasi pemasangan agar diketahui oleh masyarakat

Sumber : Admin

Tujuan : User

Media : Komputer

Frekuensi : Ketika dilokasi sudah terpasang Wifi

Bentuk : Web page

B. Rancangan Dokumen Keluaran (Output)

Adapun rancangan dokumen keluaran yang dibuat yaitu:

1. Nama Dokumen: Laporan data user pengajuan

Fungsi : Untuk mengetahui data user pengajuan

Sumber : Admin

Tujuan : Admin

Media : File

Frekuensi : Ketika data diperlukan oleh admin

Bentuk : pdf

2. Nama Dokumen: Detail status pengajuan

Fungsi : Sebagai bukti status pengajuan pemasangan

Sumber : Admin

Tujuan : User

Media : Komputer

Frekuensi : Ketika data pengajuan ditolak atau setujui oleh admin

Bentuk : Email

3. Nama Dokumen: Laporan seluruh status pemasangan Wifi

Fungsi : Sebagai bukti data pemasangan Wifi

Sumber : Admin

Tujuan : Admin

Media : Komputer

Frekuensi : Ketika data diperlukan oleh Admin

Bentuk : pdf 


\subsection{Entity Relationship Diagram (ERD)}

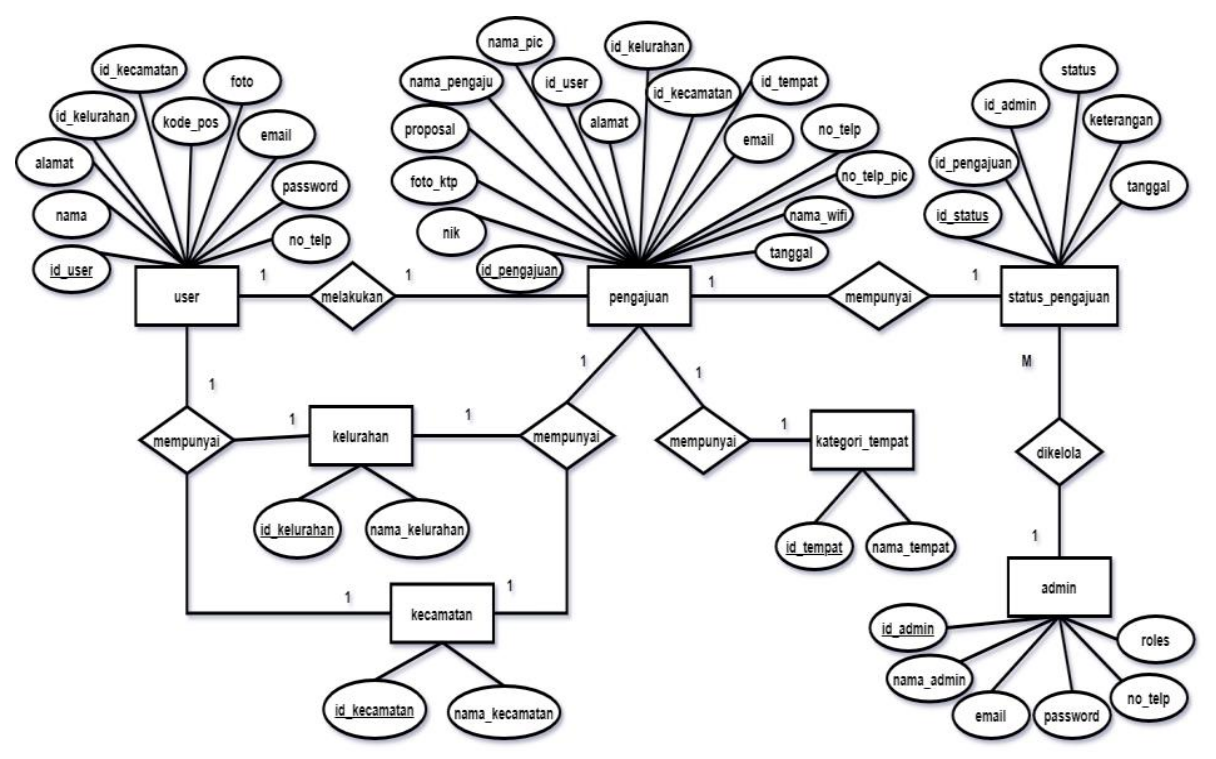

Gambar 1. Entity Relationship Diagram

\subsection{Logical Record Structure (LRS)}

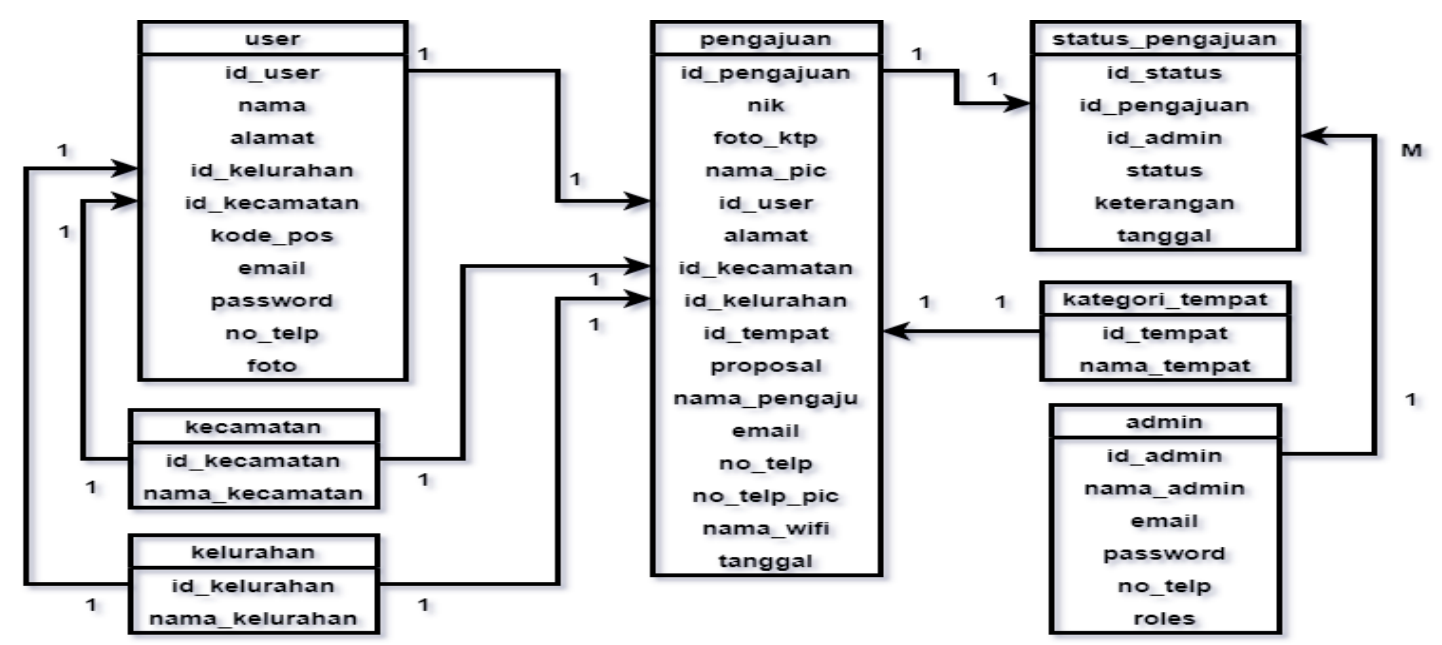

Gambar 2. Logical Relationship Diagram

\subsection{Spesifikasi Program}

A. Struktur Navigasi User

Pada struktur navigasi alur user ini menggunakan struktur navigasi composite seperti dibawah ini: 


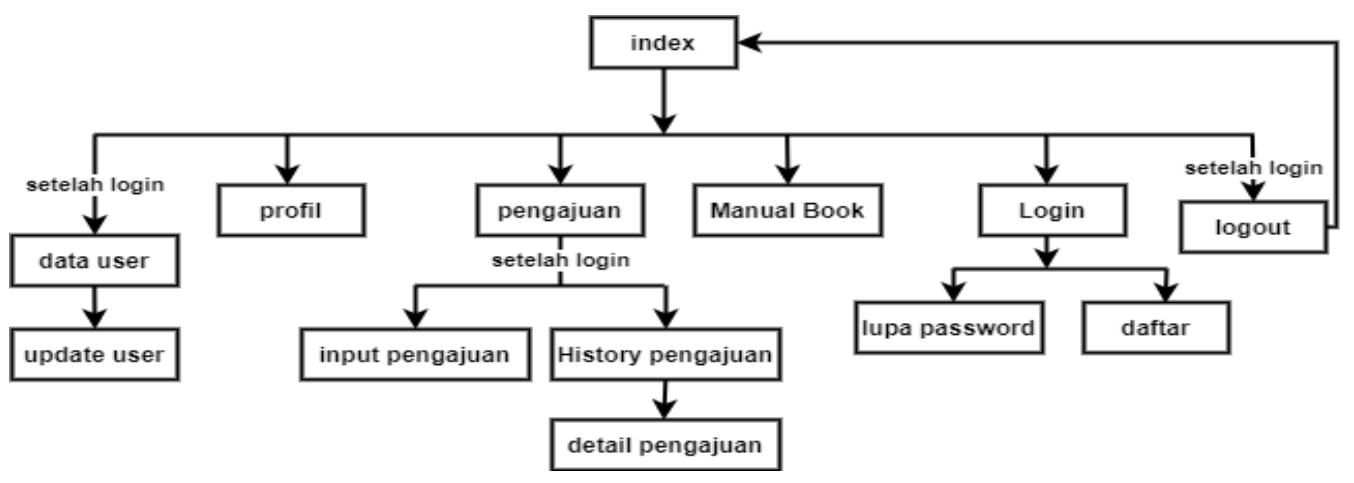

Gambar 3. Struktur Navigasi User

B. Struktur Navigasi Admin

Pada struktur navigasi alur admin ini menggunakan struktur navigasi composite seperti dibawah:

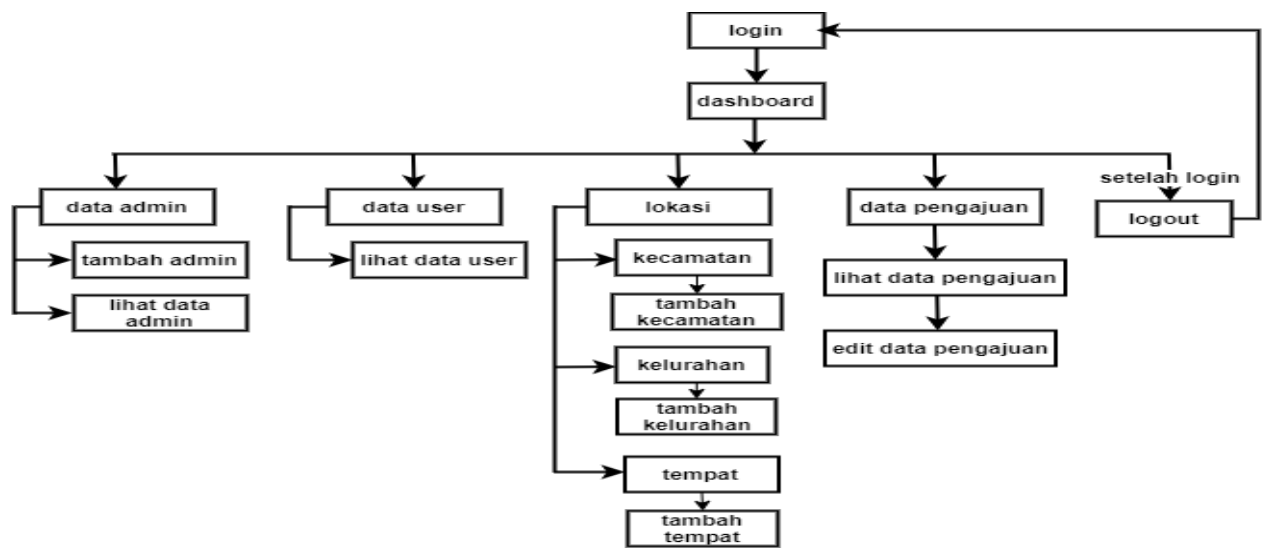

Gambar 4. Struktur Navigasi Admin

\subsection{Implementasi}

\section{A. Halaman Home}

Halaman ini dapat diakses oleh user yang sudah login dan tanpa login, pada halaman ini terdapat informasi berupa "tahapan pemasangan Wifi depok bersahabat" dan "informasi lokasi dikota Depok yang sudah terpasang Wifi publik".

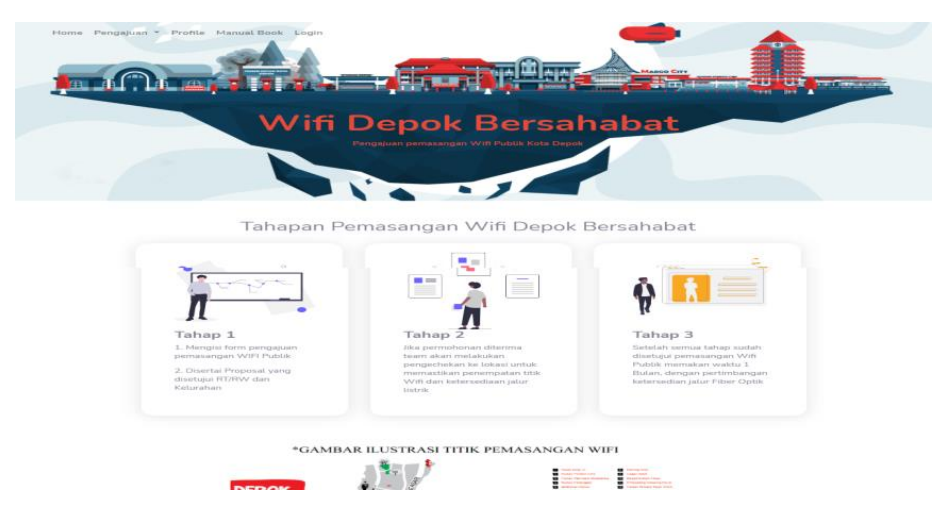

Gambar 5. Halaman Home 


\section{B. Halaman Profile}

Berisikan informasi terkiat profile website pengajuan pemasangan Wifi publik Kota Depok.

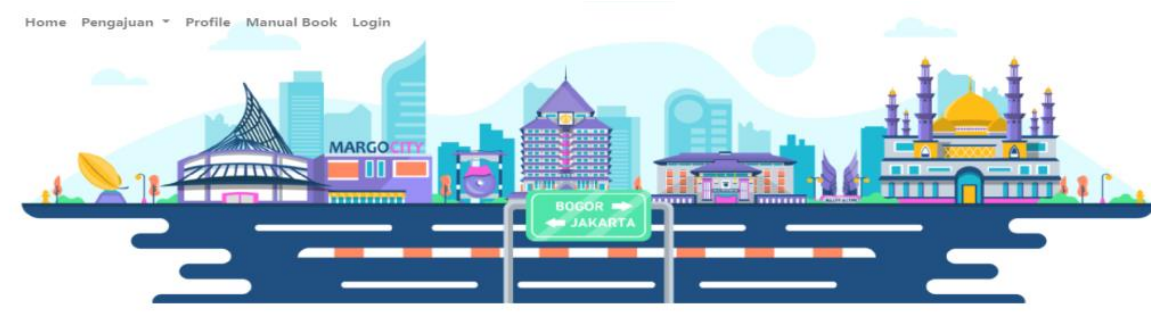

Profile Wifi Depok Bersahabat

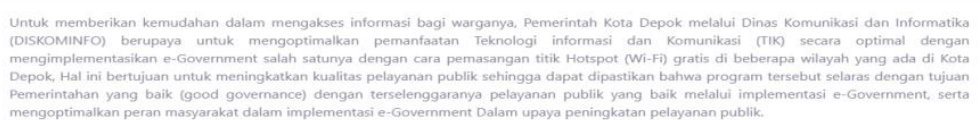

Gambar 6. Halaman Profile

C. Halaman Manual Book

Pada halaman ini berisikan informasi cara penggunaan atau aktifasi Wifi Depok bersahabat.

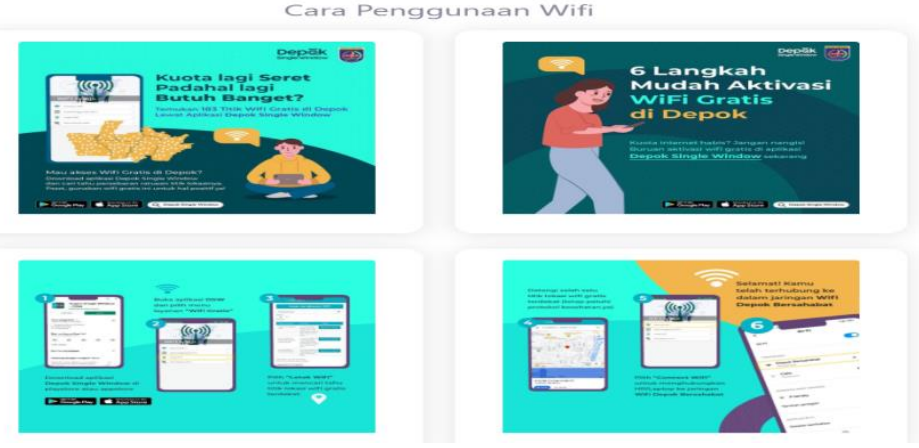

Gambar 7. Halaman manual book

D. Halaman Daftar Akun

Untuk user yang ingin mengjukan pemasangan tapi belum punya akun, dapat membuat akun terlebih dahulu pada halaman daftar akun.

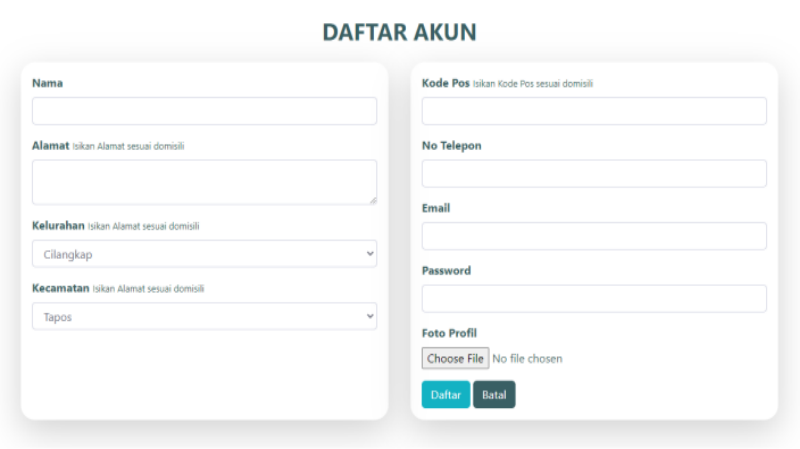

Gambar 8. Halaman Daftar Akun 


\section{E. Halaman Pengajuan}

Untuk user yang ingin mengajukan pemasangan Wifi dapat mengisi form pengajuan disana juga dijelaskan mengenai persyaratan pemasangan.
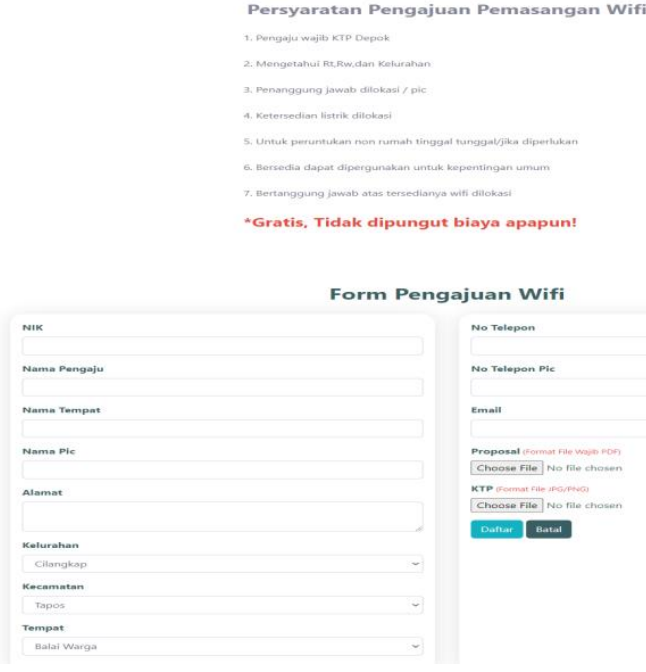

Gambar 9. Halaman Pengajuan

\section{F. Halaman Data Pengajuan}

Pada halaman data pengajuan admin dapat melihat detail pengajuan yang sudah diinput oleh user pengajuan.

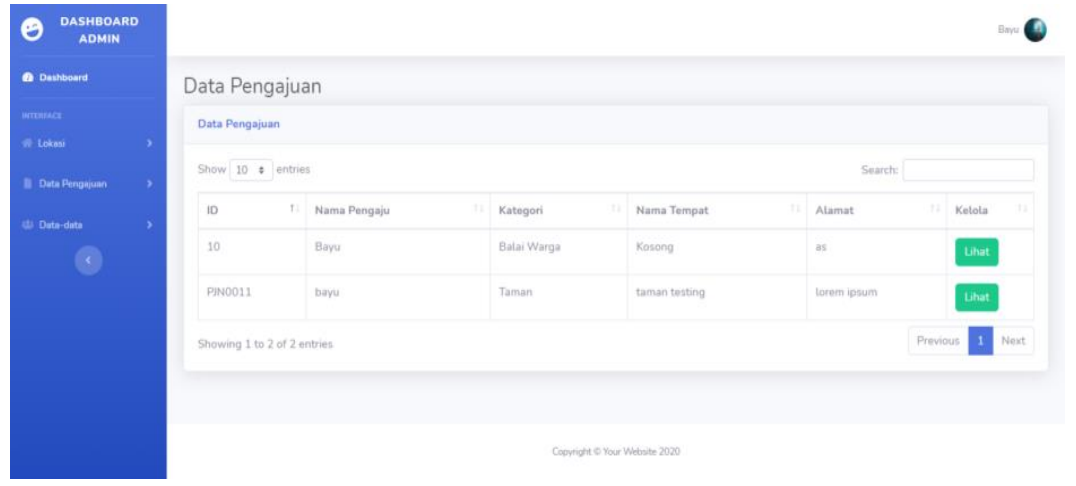

Gambar 10. Halaman Data Pengajuan

\section{Halaman Data Pengajuan / History Pengajuan}

Bagi user yang telah mengajukan pemasangan dapat melihat data pengajuan pada halaman ini serta dapat melihat status pengajuan apakah diterima atau ditolak. 

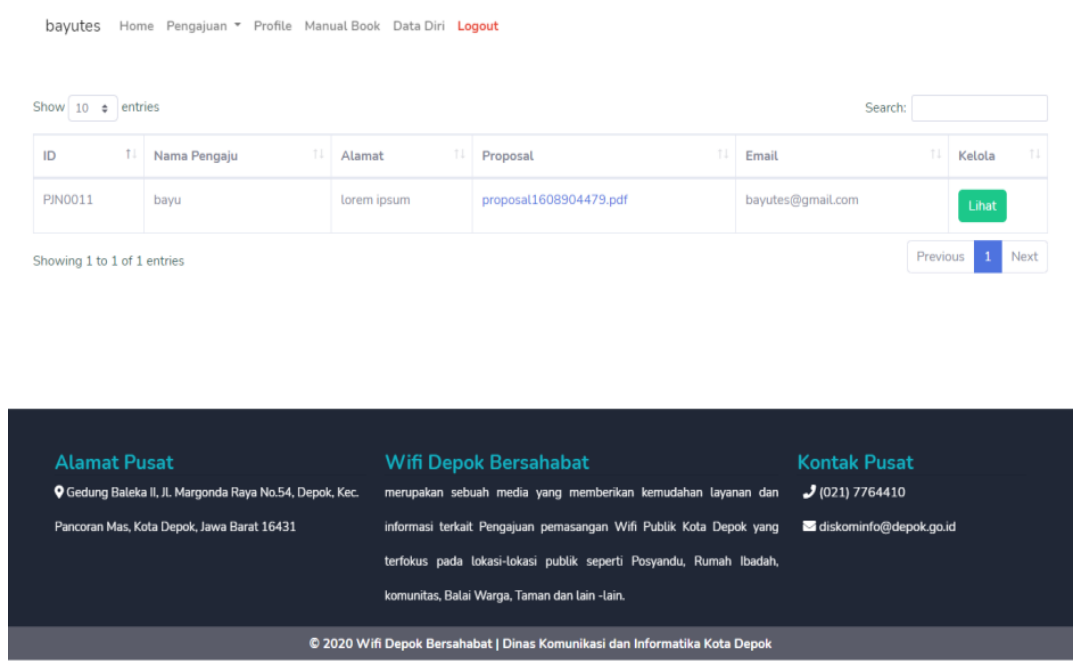

Gambar 11. Halaman Data Pengajuan / History Pengajuan

\section{KESIMPULAN}

Aplikasi Pengajuan Pemasangan Wifi Publik Kota Depok ini dapat membantu masyarakat untuk mengajukan permohonan pemasangan Wifi Publik di Kota Depok secara online. Khusus untuk Pemerintah Kota Depok aplikasi ini merupakan salah satu bentuk penerapan e-Government yang ada di Kota Depok dalam rangka meningkatkan kualitas pelayanan publik. Design website dibuat sederhana mungkin agar mudah dipahami oleh masyarakat luas serta penerapan web yang responsif agar dapat digunakan pada ponsel pintar.

Untuk pengembangan lebih lanjut, aplikasi ini dapat ditambahkan fungsi-fungsi yang lain yang terkait dengan pelayanan kepada masyarakat yang dapat dilakukan secara online, dan juga aplikasi ini dapat ditambahkan fungsi halaman informasi mengenai berita seputar pelayanan yang lain yang ada di Kota Depok.

\section{DAFTAR PUSTAKA}

Anhar.

2017.

internet

menurut

Anhar

(2017).

$8-22$.

https://repository.bsi.ac.id/index.php/unduh/item/217776/File_10-BAB-II-Landasan-Teori.pdf

Ayu, F., \& Permatasari, N., 2018. Perancangan Sistem Informasi Pengolahan Data Praktek Kerja Lapangan (Pkl) Pada Devisi Humas Pt. Pegadaian. Intra-Tech, 2(2), 12-26.

Cholifah, W. N., Yulianingsih, Y., \& Sagita, S. M., 2018. Pengujian Black Box Testing pada Aplikasi Action \& Strategy Berbasis Android dengan Teknologi Phonegap. STRING (Satuan Tulisan Riset Dan Inovasi Teknologi), 3(2), 206. https://doi.org/10.30998/string.v3i2.3048

Destiningrum, M., \& Adrian, Q. J., 2017. Sistem Informasi Penjadwalan Dokter Berbassis Web Dengan Menggunakan Framework Codeigniter (Studi Kasus: Rumah Sakit Yukum Medical Centre). Jurnal Teknoinfo, 11(2), 30. https://doi.org/10.33365/jti.v11i2.24

Dewi, M. P., Gofur, A., \& Hendarto, D., 2020. Sosialisasi dan Pendampingan Penggunaan Online Single Submission pada Pelaku Usaha Kecil dan Menengah di Kota Depok. Jurnal Komunitas, 3(1), 34-39.

Firman, A., Wowor, H. F., Najoan, X., Teknik, J., Fakultas, E., \& Unsrat, T., 2016. Sistem Informasi Perpustakaan Online Berbasis Web. 5(2).

Hariyanto, B., 2019. Sistem Manajemen Basis Data, Informatika. October. 
https://doi.org/10.13140/RG.2.2.11412.86409

Hidayat, T., \& Muttaqin, M., 2018. Pengujian Sistem Informasi Pendaftaran dan Pembayaran Wisuda Online menggunakan Black Box Testing dengan Metode Equivalence Partitioning dan Boundary Value Analysis. Jurnal Teknik Informatika UNIS JUTIS, 6(1), 2252-5351.

Jurnal Petir., 2018. Perancangan Aplikasi Penjualan Dengan Metode Waterfall Pada Koperasi Karyawan Rsud Pasar Rebo. Petir, 11(1), 9-24. https://doi.org/10.33322/petir.v11i1.3

Nurmalasari, Anna, \& Arissusandi, R., 2019. Rancang Bangun Sistem Informasi Akuntansi Laporan Laba Rugi Berbasis Web. Jurnal Sains Dan Manajemen, 7(2), 6-14.

Pahlevi, O., Mulyani, A., \& Khoir, M., 2018. Sistem Informasi Inventori Barang Menggunakan Metode Object Oriented di PT . Livaza Teknologi Indonesia Jakarta. 5(1).

Rosidah., 2018. Bab Ii Landasan Teori. Journal of Chemical Information and Modeling, 53(9), 8-24.

Ruli Erinton, Ridha Muldina Negara, D. D. S., 2017. Analisis Performasi Framework Codeigniter Dan Laravel Menggunakan Web Server Apache. EProceedings of Engineering, 4(3), 3565-3572. https://doi.org/10.1016/j.jcfm.2006.05.004

Tabrani, M., \& Eni, P., 2017. Penerapan Metode Waterfall Pada Sistem Informasi Inventori Pt. Pangan Sehat Sejahtera. Jurnal Inkofar, 1(2), 30-40.

Tias Mahdiati, E. W. F., 2016. Rancang Bangun Sistem Informasi Permintaan ATK Berbasis Intranet (Studi Kasus: Kejaksaan Negeri Rangkasbitung). Jurnal khatulistiwa informatika, IV(2), 41.

Trimarsiah, Y., \& Arafat, M. (2017). Analisis Dan Perancangan Website Sebagai Sarana Informasi Pada Lembaga Bahasa Kewirausahaan Dan Komputer Akmi Baturaja. Jurnal Ilmiah Matrik, 1-10. https://doi.org/10.33557/jurnalmatrik.v19i1.366

Web Programing, W., 2017. Membangun Sebuah Website Dari Nol Hingga Tingkat Menengah. Universitas Bina Sarana Informatika.

Yuni Eka Achyani, E. A., 2018. Sistem Informasi Pendapatan Jasa Pada Koperasi PDAM Tirta Patriot Bekasi. Jurnal Teknik Komputer AMIK BSI (JTK), 4(1), 1-8. 